\title{
WWW-intensive concept mapping for metacognition in solving ill-structured problems
}

Citation for published version (APA):

Stoyanov, S., \& Kommers, P. (2006). WWW-intensive concept mapping for metacognition in solving ill-structured problems. International Journal of Continuing Engineering Education and Life-Long Learning, 16(3/4), 297-316.

https://doi.org/10.1504/IJCEELL.2006.009205

\section{DOI:}

10.1504/IJCEELL.2006.009205

Document status and date:

Published: 01/01/2006

Document Version:

Peer reviewed version

Please check the document version of this publication:

- A submitted manuscript is the version of the article upon submission and before peer-review. There can be important differences between the submitted version and the official published version of record. People interested in the research are advised to contact the author for the final version of the publication, or visit the DOI to the publisher's website.

- The final author version and the galley proof are versions of the publication after peer review.

- The final published version features the final layout of the paper including the volume, issue and page numbers.

Link to publication

\section{General rights}

Copyright and moral rights for the publications made accessible in the public portal are retained by the authors and/or other copyright owners and it is a condition of accessing publications that users recognise and abide by the legal requirements associated with these rights.

- Users may download and print one copy of any publication from the public portal for the purpose of private study or research.

- You may not further distribute the material or use it for any profit-making activity or commercial gain

- You may freely distribute the URL identifying the publication in the public portal.

If the publication is distributed under the terms of Article 25fa of the Dutch Copyright Act, indicated by the "Taverne" license above, please follow below link for the End User Agreement:

https://www.ou.nl/taverne-agreement

Take down policy

If you believe that this document breaches copyright please contact us at:

pure-support@ou.nl

providing details and we will investigate your claim.

Downloaded from https://research.ou.nl/ on date: 26 Apr. 2023 


\title{
Running head: CONCEPT MAPPING TO SOLVE PROBLEM
}

This is a pre-print of the article that was published as

Stoyanov, S., \& Kommers, P. (2006). WWW-intensive concept mapping for metacognition in solving ill-structured problems. International Journal of Continuing Engineering Education and Lifelong Learning, 16(3/4), 297-316.

International Journal of Continuing Engineering Education and Lifelong Learning is avalilable online at http://www.inderscience.com/browse/index.php?journalID $=6 \&$ year $=2004 \& v 0 l=14 \&$ issue $=4 / 5$

\author{
WWW-intensive concept mapping for metacognition \\ in solving ill-structured problems
}

\author{
Slavi Stoyanov \\ Open University, Netherlands \\ Piet Komemrs \\ University of Twente, Netherlands
}

Correspondence concerning this article should be addressed to Slavi Stoyanov, Open University of the Netherlands, Educational Technology Expertise Centre, PO Box 2960, 6401 DL Heerlen, The Netherlands. E-mail: slavi.stoyanov@ou.nl 
Instruction on concept mapping to support learning for solving ill-structured problems

The operational support to learning for solving ill-structured problems is considered as one of the most demanding tasks of the contemporary instructional design paradigm (Jonassen, 2004). It requires introduction to specific techniques that facilitate learner to construct an appropriate solution in situations which are characterized with insufficient and sometimes vague information, existence of alternative and often conflicting approaches, lack of clear-cut problemsolving procedure and no agreement upon what can be accepted as an appropriate solution (Jonassen, 2004; Schön,1996). Some of the techniques that have been discussed are concept map, causal modeling, influence diagrams, expert system shell, modeling dynamic systems (Jonassen, 2004), cognitive flexibility hypertext (Spiro \& Jehng, 1990), and questions prompts (Ge \& Land, 2004; King, 1991). Concept map is recognized as potentially a powerful problem-solving tool but the discussion on the role of the technique in solving ill-structured problems still has to address a number of substantial questions (Jonassen, 2004, Stoyanov, 2001). Some of them are:

- What are the characteristics of concept map that make the techniques an effective and efficient problem-solving tool?

- What are the differences and similarities of concept map compared to other mapping techniques?

- Are there any individual differences in building a concept map in a situation of problemsolving?

- What is the role of the instruction in constructing a concept map as problem-solving tool? 
An attempt of providing some insights in relation to these questions is given in the following sections. Figure 1 presents a concept map on the content, that is a subject of this article.

Figure 1. Concept map on concept mapping instruction

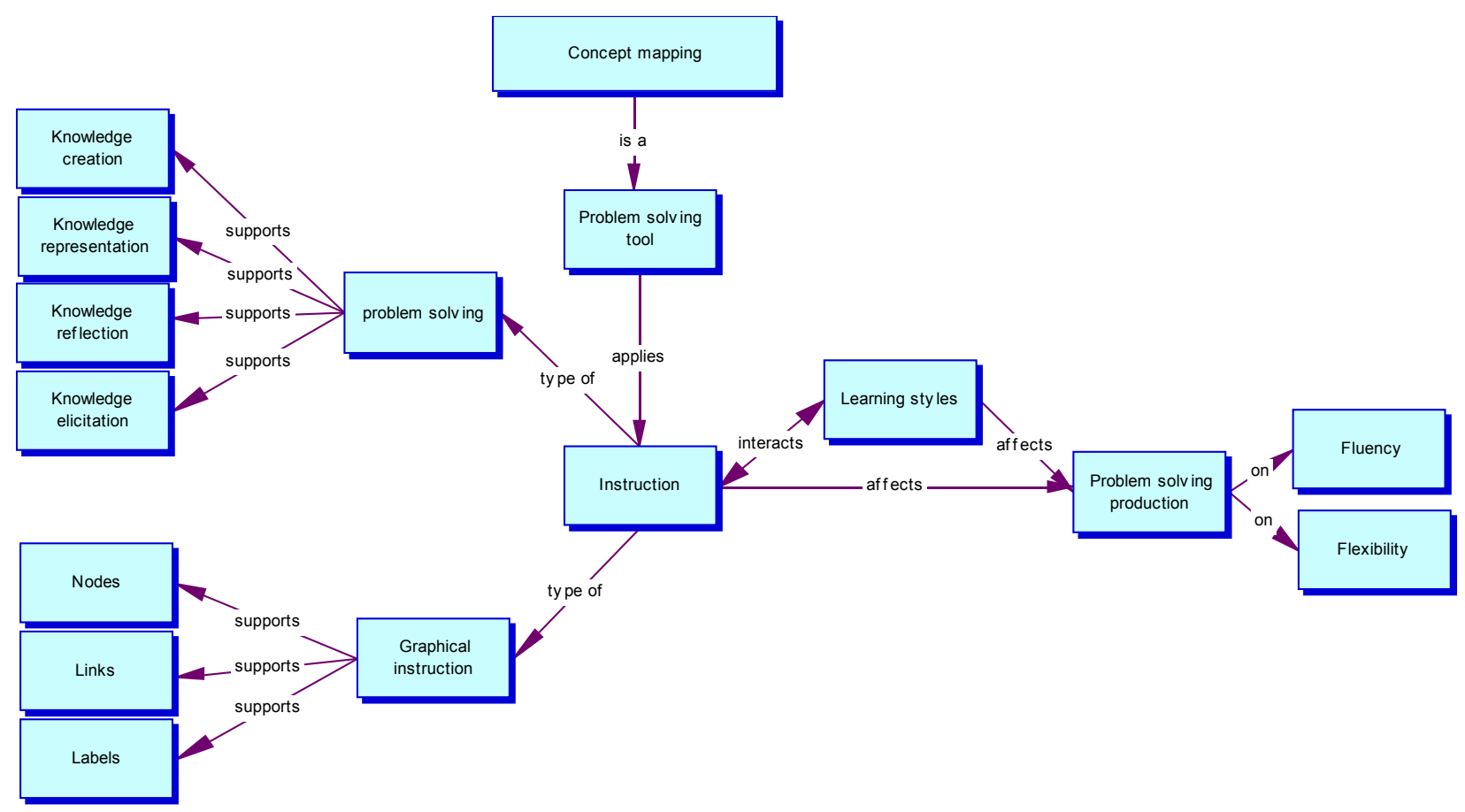

\section{Concept mapping as a problem-solving tool}

Concept map is defined as a graphical technique to represent the conceptual organization of a particular subject domain and to grasp the perception of learners on this knowledge structure (Huai \& Kommers, 2004; Jonassen, Reeves, Hong, Harvey \& Peters, 1998; Kommers \& Lanzing 1998; Novak, 1998). The terms of concept map and concept mapping have been used interchangeably. In this article, concept map refers to the result of the concept mapping process. Concept mapping technique has been used mostly as a graphical advanced organizer (Novak \& 
Gowin, 1984; Novak, 1998) and assessment technique (Constantinou, 2004; Fernandes, Kommers \& Asensio, 2004; Novak, 1998; Weber, 2004; Willerman \& Harg, 1991) from teachers, and as a learning aid for students to organize their declarative and structural knowledge (Gulmans, 2004; Jonassen, Beissner \& Yacci, 1993; Lumer \& Hesse, 2004; Lumer \& Ohly, 2004; Novak, 1998). There are relatively few reports on the role of concept mapping as a tool that supports learning for solving ill-structured problems (Jonassen, 2004; Stoyanov, 2001). Jonassen (2004) defines concept map as a tool for representing the semantic organization of problems by learners. He finds important for instructors to encourage semantic networking before students begin to solve problems.

Most of the definitions of concept mapping describe the techniques as a knowledge representation tool (Gulmans, 2004; Huai \& Kommers 2004; Jonassen, Reeves, Hong, Harvey \& Peters, 1998; Kenedy \& McNaught, 1998, Kommers \& Lanzing 1998; Reimann, 1999; Sherry \& Trigg (1996). As a knowledge representation tool, concept mapping has some features that could make it a powerful problem-solving tool (Stoyanov, 2001). The technique is an adequate, flexible and intuitive way of externalizing the mental model of problem solver. Concept map shows the pattern of knowledge items arranged in the problem space as applying a simple graphical format: nodes represent thoughts and labeled links express their interrelationships. Concept map is a concise, compact and parsimonious technique, which is at the same time rich in information, because of the integration of verbal and visual coding. The technique capitalizes on the advantages of graphical representations, without losing the flexibility and richness of the natural language system. Concept map can expresses a variety of problem-solving representations (facts, analogies, feelings) and a variety of relationships between them (descriptive, structural, causal, metaphorical). 
The definition of concept map as a knowledge representation tool reflects only one aspect of psychological conditions involved in problem-solving. Some of the issues attributed to these conditions are restricted processing and high cognitive load due to the limited capacity of working memory, difficulties with searching and retrieval in long-term memory structure, and changing the dominant thinking patterns. These limitations of cognitive system provoke some negative problem-solving effects such as functional fixedness (Duncker, 1945, cited in Eysenck \& Keane, 2000; Wertheimer, 1987), problem set (Luchins \& Luchins, 1991, cited in Eysenck \& Keane, 2000; Wertheimer, 1987) and analysis paralysis (Kaufman, 2001; Wodtke, 1993). What makes concept mapping a powerful problem-solving technique is that it is not only knowledge representation tool, but it has also a potential to be knowledge elicitation, knowledge reflection and knowledge changing tool (Stoyanov, 2001).

Concept mapping as knowledge elicitation tool supports the access to and the search in the longterm memory structures. It allows a quick recognition and retrieval of the available knowledge because of the isomorphic correspondence between map and cognitive structures (Eysenck \& Keane, 2000; Wandersee, 1990). Concepts and labels can act as cues for guiding the search through problem-solving space (Newel \& Simon, 1972). In addition the visual presentation of mental patterns makes easier pattern recognition. Recognition is a faster cognitive process than retrieval, but also contributes to a more effective retrieval (Eysenck \& Keane, 2000). Illstructured situations not always require development of a completely new solution. The most appropriate solution for a given problem-solving situation may already exist. The question however is to find it as performing broad and deep search and checking many alternatives. As knowledge reflection tool concept map supports the cognitive processes related to effective functioning of working memory. Concept map is a cognitive artifact that allows problem solver 
to look at his/her mental model and to reflect on the outcomes of thinking. Apart from this support to reflection-on individual cognitive reality, concept mapping supports reflection-inaction (Schön, 1996) of cognitive processes as well. The nature of ill-structured problem-solving situations make difficult for people to look inside and control their thinking processes. Two parallel processes are running always - thinking about the problem itself and thinking about thinking. Concept mapping can be beneficial in such sort of situations as externalizing the internal problem-solving patterns and stimulating the metacognitive functions of self-appraisal. In this way it enhances the internal locus of control on problem-solving processes. Concept map has a potential to reduce the cognitive load, which is a recognized threat for successful learning (Sweller, Merriëenboer, \& Paas, 1998). As a cognitive artifact, concept map is an external extension of working memory. It makes possible for problem solver to grasp complex interactions among thoughts that could otherwise exceed problem solver cognitive capacity. The externalization of mental problem-solving representations involves effectively perception, which amplifies the performance of memory and thinking. It frees up cognitive resources necessary for memory and thinking .

As knowledge changing tool, concept map has a potential to change the dominant thinking pattern and to create a new one (if needed) that reflects better the problem-solving situation. The technique allows manipulation of problem-solving representations. As a cultural artifact, concept map mediates the interaction of a problem solver with the objective problem-solving situation (Vygotsky, 1978). It is a sort of 'transitional object' (Eden \& Ackerman, 2003; Lane, 1997) representing mental models, which problem solver can play with. The position of knowledge items and spatial configuration can be changed purposely in order to see different perspectives and to explore new possibilities. This leads to a generation of new ideas. Working upon a concept 
map we are building upon our cognitive structures. While improving, modifying or changing completely the external model of a thinking pattern, we are improving, modifying or changing this pattern effectively. The potential of concept mapping to change the problem-solving patterns in ill-structured situations is one of the most distinguished characteristics of this technique. Concept mapping supports mental imagery. Mental imagery is beneficial for problem-solving because of the possibility to tap the perception directly, which lead to a rapid anticipation of transformations in a problem situation.

\section{Concept map as a part of the cognitive mapping paradigm}

Concept mapping is a member of the cognitive mapping family, which includes among other causal mapping (Eden \& Ackerman 2003), dynamic mapping (Vennix, 1997), mind mapping (Buzan \& Buzan, 1996), and hexagon mapping (Hodgson, 1999). The discussion on the role of concept mapping in problem solving does not provide sufficient information about the specific characteristics of concept mapping that make it a more appropriate problem-solving tool than the other mapping approaches (Jonassen, 2004). A comparative analysis of the theoretical background, procedures and software of different mapping approaches is given elsewhere (Stoyanov, 2001). For the purposes of this study we provide just a short description of these characteristics of concept mapping as a problem-solving tool.

Although referring to different theories, all of the aforementioned cognitive mapping approaches have map as an explicit metaphor. They use a non linear spatial format to represent the way knowledge items are interconnected. The theories behind the different mapping procedures provide empirical evidence that human mind stores and organize information in a map format. There are however some substantial differences in the way the mapping approaches represent cognitive constructs involved in problem-solving. Concept map is the only mapping technique 
that allows different formats of spatial organization of ideas. It can be either hierarchy or network, as network itself opens many possibilities. Causal mapping directly suggests a hierarchical structure, while mind mapping imposes a hierarchy without an explicit reference to this type of organization. Causal mapping and dynamic mapping apply mostly unlabeled causal links. The graphical organization of mind mapping suggests structural links. The relationships can be other than structural, but they are not explicit and the reader has to make inferences about their type. Hexagon mapping does not use links at all. Concept map is the only technique that provides opportunity for applying any sort of labeled idiosyncratic links. The graphical conventions of concept mapping make the technique the most flexible and expressive mapping technique (Alpert, 2004; Heeren \& Kommers, 1991).

\section{Concept mapping and individual differences}

The cognitive structures and processes modeled by concept map have individual dimensions. It should be expected that concept map reflects the effects of the individual constructs involved in problem-solving (Huai \& Kommers, 2004; Jonassen, 2004; Lanzing, 1998; Oughton \& Reed, 2000; Stoyanov, 2001). If an individual construct is involved, we should be able to identify it in the specific graphical organization of the concept map components. The taxonomy of individual differences consists of constructs such as knowledge, cognitive styles, learning styles, personality traits to list but a few. Important issues related to the individual constructs are their large number and diversity, multi-layers structure, and instability over time, space and task. The reported issues can be managed for research and design purposes through a selection of the stylistic preferences as a representative for individual differences. We use the term 'stylistic preferences' referring to either learning style or cognitive style. Stylistic preferences are an integrative 
construct including abilities and personality dimensions. Stylistic preferences play an intermediate role between abilities and behavior.

The research on relationships between concept mapping and styles returns some inconsistent data. Ayersman and von Minden (1995) reported no significant difference among Kolb's learning styles of diverger, assimilator, converger and accommodator (Kolb, 1998) in relation to hypermedia knowledge. In contrast, Oughton and Reed (2000) found an interaction effect between Kolb's learning styles and level of prior hypermedia knowledge on several features of concept mapping production such as number of concepts, number of links, level of depths, preserved concepts, omitted concepts, and added concepts. Assimilators and divergers were the most productive on their maps and had the deepest level of processing on their maps. Huai and Kommers (2004) measured the effect of cognitive styles, knowledge dimensions and concept mapping approaches on learning achievements. The cognitive styles are holist, serialist, unknown styles and versatiles (Pask, 1988). Knowledge dimensions were defined as declarative and procedural knowledge. Two concept mapping approaches were developed: globalisic and specialistic. The gobalistic approach was designed to match the holistic dimension of cognitive style. The specialistic concept mapping approach was designed to match the serialistic dimension of cognitive style. The findings of the study do not suggest an effect of concept mapping at cognitive style level. In addition, it was not found whether style's accommodation or compensation affects the learning achievements. In earlier research Huai (2000) assumed relationships between cognitive styles (holist/serialist), type of memory (short term/long term), and concept mapping method (serialistic/globalistic) on learning outcomes. She reported a relationship between cognitive style and type of memory. Holists try to compensate their weak 
short term memory with globalistic concept mapping approach. Serialist having good short term memory adopt a serialistic concept mapping approach.

\section{Instruction on concept mapping}

The characteristics of concept mapping as knowledge representation tool support the assumption that the instruction on concept mapping based on graphical conventions automatically makes the technique an effective problem-solving tool ( Jonassen, 2004). This argumentation can be used for other characteristics of concept mapping, namely a problem solving tool for knowledge elicitation, knowledge reflection and knowledge changing. Applying concept mapping graphical conventions is considered as a sufficient condition for making concept mapping an effective problem-solving tool. Our observation on using concept mapping to support learning of designing software applications for educational and training purposes suggests that it might not be the case. The instruction based on graphical conventions of concept mapping is a necessary but not a sufficient condition for making concept mapping an effective problem-solving tool. There should be another type of instruction that takes into consideration the characteristics of problem-solving process. It introduces a set of heuristics and more concrete techniques that support the cognitive processes of knowledge elicitation, knowledge representation, knowledge reflection, and knowledge creation in each of the problem-solving phases, namely, analysis of problem situation, idea generation, idea selection and solution implementation. It is this type of concept mapping instruction that transforms the possibility to be an effective problem solving tool into reality. Some of the other mental mapping approaches apply a problem-solving instruction in addition to the instruction on graphical conventions. Dynamic mapping (Vennix, 1997) uses Delphi and Nominal group techniques. Hexagon mapping (Hodgson, 1999) proceeds with some of the principles and techniques of lateral thinking (De Bono, 1990). The problem 
related to the type of instruction that makes concept mapping an effective problem solving tool in ill-structured situations brings two hypothetical ideas. One assumes that the instruction on graphical conventions is sufficient condition for making concept map an effective problemsolving tool. Another assumes that the instruction on graphical conventions should be complemented with some problem-solving heuristics and techniques. The two instructions together constitute the necessary and the sufficient conditions for concept mapping to be an effective problem-solving tool. The graphical instruction on concept mapping applies the classical procedure introduced by Novak and Gowin (1984). The problem-solving instruction, developed for the purposes of this study, took into consideration the problem-solving process. For each of the stages of problem-solving process, a number of heuristics was suggested (for details see Stoyanov, 2001, p. 175-177). The set of heuristics was based on the strong points of the rational approaches to problem-solving such as explicitness, generality and soundness (Wagner, 1992), but also took into account the intuitive, non linear and thinking-while-doing way people approach problems (Mintzberg, 1992, Schön, 1996, Wagner, 1992). The problem solving guidelines reflected brainstorming principles (Osborn, 1963 cited in Van Gundy), rational problem-solving approach (Kepner, \& Tregoe, 1981, cited by Van Gundy, 1997), synectics method (Gordon, 1961, cited in Van Gundy, 1997), and lateral thinking techniques (De Bono, 1990). The heuristics were aimed at supporting knowledge elicitation, knowledge representation, knowledge reflection and knowledge changing. Some randomly taken examples for heuristics that support knowledge elicitation during problem-solving phase of analysis of the situation are:

Try to scan everything you know about the problem situation. Map everything that comes spontaneously to your mind, as one items is built upon another. The items might be existing solutions, facts, hunches, metaphors, feelings. Produce as many 
information items as possible. Avoid any attempt to judge them during the process of free association.

Some examples for knowledge reflection heuristics are:

Make an evaluation trip on the map. Remove or change (if it is necessary) some of the nodes and some of the links. Try to improve your map.

Some examples for knowledge representation guidelines are:

Try to make clusters. Draw and label links between items. The links can be descriptive (is a), structural (part of, belongs to), causal (leads to, influenced by), or metaphorical (like).

An example for knowledge changing heuristic is "Change the spatial configuration of the map, if necessary."

Some guidelines that support knowledge elicitation during idea generation phase are as follows:

Look at the map analysis of situation that just has been made. Start to formulate solution by scratch, as many as possible. Write down everything that pops-up to your mind without any judgment.

An example for knowledge changing heuristic during the idea generation is the following:

Take randomly one of the marginal concepts and put it at the very central place of the map. Try to reconfigure the map from this new perspective. Use the new vision as a stimulus for a free association in order to generate as many ideas as possible.

Play with labels. Randomly select a pair of nodes and change the links' label. Use this as a provocation for producing as many solutions as you can. 
An example for knowledge representation heuristics during the idea generation is the following:

Draw a resulting map containing all ideas generated. Link the nodes and label the links as is a; part of, like; leads to, and etc.

An example for knowledge reflection heuristic during the idea generation phase is the following:

Try to find a trend or pattern among the ideas you have generated. Is it possible to make clusters? If you find repetition of some of the ideas, it should attract your attention. Try to add some more ideas.

In addition to investigating the effectiveness of the concept mapping instruction method, we want to determine the role of individual differences in each of the two hypothetical conditions. To test the validity of the assumptions we design and conduct an experiment. The research questions that are going to be addressed are as follows:

What is the effect of concept mapping instruction method on solving ill-structured problems?

What is the effect of individual differences on the construction of concept maps in a illstructured problem-solving situation?

Method

The experimental method applied a factorial experimental design (2x2) with a post-test control group. This experimental design was selected because a random assignment to the conditions was possible at a certain stage. The combination of random assignment and a control group served to eliminate the majority of threats to both the external and internal validity of the study. Although the proportion of dropouts was reported as a potential threat to internal validity, not controlled for this type of design, it did not prove to be a problem in the current study. The research was 
conducted in a one-day session and the size of groups remained constant throughout the duration of the study.

The experimental design included two independent variables: type of instruction on concept mapping and learning style. The type of instruction had two levels: the classical concept mapping instruction method and the new concept mapping instruction method. The new concept mapping instruction method introduced a set of problem-solving heuristics in addition to the concept mapping graphical conventions.

The experimental design defined learning style as a second independent variable. It had also two levels: doers and thinkers. Learning style should be controlled because of the possibility of being a source of alternative explanation of the effect of instruction on mapping production, if found. This variable was included in the experimental design schema as a second independent variable because it was expected to be a good predictor for a possible differential effect on mapping production and a possible interaction effect with the type of concept mapping instruction.

The dependent variable in this study was concept mapping production. The operationalization of the variable is based on the approach of Novak and Gowin (1984) in scoring concept maps and the criteria for creative thinking developed by Guilford (1967), both adapted for measuring the effectiveness of concept mapping instruction.

The operationalization of the dependent variable included two criteria, each having several indicators. These criteria were broad perception and divergency. Broad perception defined the extent to which problem solver represents comprehensively the problem situation. The indicators that described this criterion were as follows:

- Fluency: a) number of nodes; b) number of links 
- Flexibility: a) variety of nodes - facts, data, metaphors/analogies, personal experience, opinions, hypotheses, feelings; b) variety of labels: descriptive, structural, causal, interrogative, and remote associations; c) variety of links (one-directional, bi-directional, and cross-links).

Divergency was defined as the extent to which problem solver produces alternative solutions. The indicators that described this criterion were:

- Fluency - number of ideas;

- Flexibility: variety of ideas: ready-made solutions, elaboration, suggestions, and unconventional ideas.

The study tested two hypotheses. The first hypothesis states that the experimental group using the new method for concept mapping instruction will score significantly higher on mapping production than the control group, which applies the classical concept mapping instruction method. According to the second hypothesis individual differences in learning styles will prove a good predictor for the differences in mapping production and will generate an interactive effect with the type of instruction.

\section{Subjects and Instrument}

Fifty-two fourth-year undergraduate students were tested for their learning style. Thirty two of them were randomly selected and then were equally assigned to the experimental and the control group, according to their learning styles. As a reinforcement to increase the motivation of the students to participate in the experiment, several demo versions of mapping software tools were installed for free to be used after the experiment. 
The Learning Style Questionnaire (LSQ) of Honey and Mumford (1992) was used to measure learning styles of students. It consists of eighty items to identify four learning styles: Activist, Reflector, Theorist, and Pragmatist. The instrument is a psychometrical validation of Kolb's (1998) experiential theory but provides better internal consistence of items than the original Kolb's Learning Style Inventory (see for more details de Ciantis \& Kirton, 1996). The test-retest reliability of the LSQ is reported to be high - .89. In order to ensure better representation of learning styles for the purposes of this experiment, the four scales were merged into two Thinkers (Theorists and Reflectors) and Doers (Activists and Pragmatists). Honey and Mumford (1992) recommended reducing the four styles to two for research purposes.

The reliability of mapping production coding was checked as well. Firstly, two evaluators independently coded six maps each (three from the experimental group and three from the control group) and compared the results of their scoring. The intercoder reliability was a relation between the number of agreements and the total number of agreements and disagreements (Miles \& Huberman, 1994). The intercoder reliability initially got the value of $80 \%$. Because this was assumed as not a very high reliability, the two evaluators discussed the value of each of the indicators in order to make closer their judgements. The discussion increase the value of the intercoder reliability to $95 \%$.

\section{Procedure}

The learning style questionnaire was distributed among the subjects to be filled in. Based on the results, the students were proportionally assigned to the control and the experimental groups in order for both learning styles (thinkers and doers) to be equally represented.

The students in the control group were introduced to the classical concept mapping method. The experimental group had to apply the new concept mapping instruction method. 
A case to be solved was presented to the students in both the control and the experimental group and they were asked to use the procedures they had been introduced to solve the case. The case, called the 'George's Career Dilemma' represents a situation in which a last year university student is confronted with a problem to take decision about his future.

\section{Results}

Two-way analysis of variance (ANOVA) was chosen as an appropriate statistical procedure for the factorial experimental design applied in this study. The fixed factors were concept mapping instruction and learning style. The dependant variable was mapping production. An alpha level of .05 was used for all data analysis.

The experimental group scored significantly higher than the control group on the indicator fluency of nodes of the broad perception criteria $-\mathrm{F}(1,28)=6.297, \mathrm{p}=.018$. (See Table1 for the direction of concept mapping instruction effect).

\section{Table 1}

Mean figures of Broad Perception - nodes

\begin{tabular}{lcccc}
\hline Nodes & \multicolumn{2}{c}{ M } & \multicolumn{2}{c}{ SD } \\
\hline & Classical & New & Classical & New \\
\cline { 2 - 5 } Number of nodes & 10.7 & 16.8 & 3.5 & 8.8 \\
Variety of nodes & 2.1 & 4.7 & 0.4 & 1.3 \\
Facts & 71.9 & 48.5 & 7.6 & 10.2 \\
Opinions & 27.9 & 13.9 & 7.6 & 10.6 \\
Feelings & 0.6 & 14.6 & 2.2 & 7.2 \\
Metaphors \& Analogies & 0.3 & 4.2 & 1.3 & 5.2 \\
\hline
\end{tabular}

$\mathrm{N}=32$ (Classical concept mapping instruction - 16; New concept mapping instruction -16)

The subjects in the experimental group produced considerably more information items than the subjects in the control group. The experimental group also demonstrated significantly higher results on the flexibility of nodes $-\mathrm{F}(1,28)=55.446, \mathrm{p}=.0001$. The distribution of the different 
types of nodes shows that the students in the experimental group included relatively much more statistical data and figures $-\mathrm{F}(1,28)=12.802, \mathrm{p}=.000$, personal experience $-\mathrm{F}(1,28)=11.510$, $\mathrm{p}=.002$, hypotheses $-\mathrm{F}(1,28)=13.810, \mathrm{p}=.001$, feelings $-\mathrm{F}(1,28)=62.837, \mathrm{p}=.000$, and metaphors and analogies $-\mathrm{F}(1,28)=8.269, \mathrm{p}=.008$, than the students in the control group. No one of the maps in the control group contained the following types of nodes: statistical data and figures, personal experience, and hypotheses. The perception of the problem space in the control group was dominated mostly by facts $-\mathrm{F}(1,28)=50.948, \mathrm{p}=.000$ and opinions $-\mathrm{F}(1,28)=$ $17.372, \mathrm{p}=.000$. The data show that the new concept mapping instruction method stimulates students in the experimental group better to express the complexity of their problem-solving representations than the students applying the classical concept mapping instruction. Students in the experimental group use not only facts but also feelings, metaphors and analogies, and assumptions types of nodes.

There was not a significant difference between the experimental and the control group on the indicator fluency of links (Table 2 presents mean values of the Broad Perception - links indicators).

Table 2

Means figures of Broad Perception - links

\begin{tabular}{lcccc}
\hline Links & \multicolumn{2}{c}{ M } & \multicolumn{2}{c}{ SD } \\
\hline & Classical & New & Classical & New \\
\cline { 2 - 5 } Number of links & 17.8 & 17.9 & 5.7 & 9.7 \\
Variety of links & 2.4 & 1.6 & 0.6 & 0.8 \\
One-directional links & 76.4 & 95.2 & 15.8 & 8.8 \\
Bi-directional links & 12.8 & 2.2 & 12.7 & 5 \\
Cross-Links & 10.2 & 4.6 & 8.2 & 7 \\
\hline
\end{tabular}

$\mathrm{N}=32$ (Classical concept mapping instruction - 16; New concept mapping instruction - 16) 
As the students in the experimental group produced more nodes, the students in the control group use relatively more links per node. The subjects working with the classical concept mapping instruction scored significantly higher than their fellows in the experimental group on the relative number of bi-directional $-\mathrm{F}(1,28)=9.965, \mathrm{p}=.004$, and cross-links $-\mathrm{F}(1,28)=5.029, \mathrm{p}=$. 033. The students in the experimental group use mostly one-directional links - F $(1,28)=16.490$, $\mathrm{p}=.000$. A possible explanation might be that subjects using the classical method were forced to use the whole repertoire of possible links because they had to represent everything on one sheet of paper. The students in the experimental group had more room to place their problem-solving representations because of the instruction to make at least two maps - one for analysis of problem situation and one for idea generation. This particular feature of the new concept mapping instruction gave the subjects in the experimental group more memory space, mapped into different sections - analysis of problem situation and idea generation. . While the traditional method put all the problem-solving activities in one picture, the new concept mapping instruction created a picture of the whole problem-solving process, sharing the cognitive load between the problem-solving stages. While the simplicity of the types of links freed up the memory processes, the complexity of the labels' structure provided a deeper perception of the problem-solving space.

The variety of link labels $-\mathrm{F}(1,28)=5.645, \mathrm{p}=.025$, was greater in the experimental conditions (Table 3 shows the mean figures of links' labels).

Table 3

Means figures of Broad Perception - labels

\begin{tabular}{lcccc}
\hline Labels & \multicolumn{2}{c}{ M } & \multicolumn{2}{c}{ SD } \\
\hline & Classical & New & Classical & New \\
\cline { 2 - 5 } Variety of labels & 2.8 & 3.4 & 0.6 & 0.9 \\
Descriptive labels & 53.3 & 25.9 & 24.4 & 16.6 \\
Structural labels & 7 & 14.2 & 7.1 & 7.8 \\
Causal labels & 4.5 & 7.6 & 3.6 & 3.6
\end{tabular}




\begin{tabular}{lllll}
\hline Interrogative labels & 0.4 & 2.8 & 1.5 & 3.9 \\
\hline
\end{tabular}

$\mathrm{N}=32$ (Classical concept mapping instruction - 16; New concept mapping instruction - 16)

The students in the classical concept mapping instruction group used predominantly descriptive types of links' labels $-\mathrm{F}(1,28)=12.948, \mathrm{p}=.001$. They did not use remote association labels at all. The experimental group used more structural $-\mathrm{F}(1,28)=8.483, \mathrm{p}=.007$, causal $-\mathrm{F}(1,28)=$ $6.192, \mathrm{p}=.019$, interrogative $-\mathrm{F}(1,28)=5.358, \mathrm{p}=.028$, and remote associative $-\mathrm{F}(1,28)=$ $13.064, \mathrm{p}=.001$, links. The new method used a more complex verbal code combined with a simpler link structure. It provided a deeper perception of the problem space while reducing the cognitive overload.

The experimental group was superior to the control group in regard to the criteria of divergency. The scores on number of ideas, $\mathrm{F}(1,28)=20.171, \mathrm{p}=.000$, and variety of ideas, $\mathrm{F}(1,28)=$ $9.031, \mathrm{p}=.006$, were significantly higher than the same indicators of the control group. (See Table 4 for some descriptive statistics data).

Table 4. Means for indicators of Divergency

\begin{tabular}{lcccc}
\hline Divergency & \multicolumn{2}{c}{ M } & \multicolumn{2}{c}{ SD } \\
\hline & Classical & New & Classical & New \\
\cline { 2 - 5 } Number of ideas & 3.3 & 12.5 & 1.5 & 8.6 \\
Variety of ideas & 1.1 & 1.9 & 0.3 & 1 \\
\hline
\end{tabular}

$\mathrm{N}=32$ (Classical concept mapping instruction - 16; New concept mapping instruction - 16)

Certainly the results were expected as far as the control group did not get an explicit instruction of using all these types of nodes, links and types of labels. However, the data revealed at least three important facts: a) the new concept mapping instruction worked and supported a good problem solving performance, b) with the classical concept mapping method, people tend to use particular types of nodes, links, and labels, and c) the expressiveness of knowledge representation can be improved. 
The analysis of the learning style variable showed that Thinkers tended to use significantly more structural types of links than the Doers $-\mathrm{F}(1,28)=4.419, \mathrm{p}=.045$. They also formulated substantially more assumptions items than doers. The result is close to being a significant at the 0.5 level of probability $-\mathrm{F}(1,28)=3.851, \mathrm{p}=.060$. Thinkers naturally tend to classify information and to present it into clusters. They tend also to generate more hypotheses. A good prerequisite for this is a well-established structure. Doers expressed more feelings in the perception of the problem-solving space $-\mathrm{F}(1,28)=4.047, \mathrm{p}=.054$. This is probably because they are more extravert-oriented people. With the new instruction Thinkers reduced considerably the number of cross-links $-\mathrm{F}(3,26)=5.722, \mathrm{p}=.024$. Thinkers applying the classical concept mapping approach needed more cross-links to express the structural complexity of the problemsolving space. The new instruction gave them opportunities to distribute the structural complexity among several maps.

The data showed no interaction effect between the two independent variables Instruction and Style on the dependent variable of Map Production. The new concept mapping instruction proved to have a general beneficial effect across all learning styles.

\section{Discussion}

The experimental results support the hypothesis that the new concept mapping instruction method is significantly better than the traditional concept mapping instruction in a problem solving situation. The question however is how and why it is a better instruction method for solving illstructured problems. The new instruction method proves to be more effective in the analysis of problem situation and the idea generation. It enables a broaden perception with more and diverse information items and more complex labels on the links. The new problem solving instruction promotes a broader and more complex cognitive structure with a dominance of the structural, 
interrogative, causal and remote associative types of links. The classical concept mapping method used more simple descriptive types of links..

The new concept mapping instruction gives more space for scanning not only cognitive but also affective problem-solving representations. The psychological distance between the types of information items on the scale of objectivity-subjectivity is larger in the experimental group.

Data, for example, are very objective and feelings are very subjective. This increases the possibility for breaking the fixedness of existing patterns and stimulates creative combinations in the idea generation phase.

The students in the experimental group knew that they would start with the map analysis of problem situation and then they would continue with constructing the map idea generation. The externalization of cognitive and affective structures by a sequence of maps involves perception. Perception itself takes over some of the mental tasks during problem-solving, thus contributing to reducing the memory overload. It makes the reasoning processes more easy and flexible. While the traditional method draws one picture trying to include all problem-solving activities, the new type of instruction creates a picture of the whole problem-solving process distributing the cognitive load between the problem-solving stages. The new method brings a perspective and a direction to the activities. It is a cognitive aid for guiding and planning through the stages of problem-solving. The problem-solving instruction supports not only reflection-on a particular map production (analysis of situation, or idea generation). The students in the experimental group produced several versions of the map analysis of problem situation and the map idea generation as a result of reflection on their mapping production. 
Although the data did not support the assumption for an interaction effect between concept mapping instruction method and learning style, the experimental results suggested that the new concept mapping instruction method brought a general beneficial effect regardless of different learning styles. It tends to develop skills, which are not prerogative to no one of the styles. Thus the method has the potential to develop a comprehensive versatile style.

The new concept mapping instruction method produced better results than the classical concept mapping instruction because the new method operationally supported the cognitive conditions of knowledge elicitation, knowledge reflection, knowledge representation and knowledge changing. In general, the number of nodes and links of broad perception criterion and number of ideas of divergency criterion are indicators of knowledge elicitation. The variety of nodes, links (broad perception), and ideas (divergency) are operationalisations of the knowledge representation. Knowledge reflection can be expressed by the extent to which clusters and patterns are identified. Knowledge changing implies a number of original solutions that have been generated (divergency).

Knowledge elicitation. The new concept mapping instruction method offers special techniques for a broad and deep retrieval of cognitive and affective structures during the analysis of problem situation. In the idea generation phase the new instruction method stimulates production of many alternative solutions. The heuristics that it applies are combinations between some problem-solving techniques and the specific characteristics of cognitive mapping.

Knowledge representation. The new concept mapping method promotes a variety of problem-solving types of representations and a variety of links between them to build a meaningful network when exploring a problem-solving space. It stimulates using not only 
objective (facts, statistics) but also subjective (feelings, intuitions, assumptions.) knowledge items. The method manages the complexity of a problem-solving situation through a set of different types of links: descriptive, structural, causal, and remote associative. The new concept mapping method has a capacity to represent very rich picture of a problem situation as combining verbal and visual coding within a simple graphical format. The externalization of the mental problem-solving representations frees up and extends the limited capacity of working memory thus reducing the cognitive overload.

Knowledge reflection. The new instruction method on concept mapping makes the internal problem-solving representations explicit. A problem solver is able to reflect-on the results and the process of problem-solving. The new concept mapping instruction method offers some guidelines and techniques for organizing the problem-solving space in a particular way. Mostly it is the case of some convergent activities within each of the phases of the method. Knowledge reflection, for example, is supported by the suggestions for reorganizing the problem space, more specifically, clustering some of the items and eliminating others. The visualization of the problem space through cognitive maps helps the manipulation of the knowledge items in a variety of ways. Because of the close correspondence between internal mental structures and the external mode of their representation one could change the way she or he looks at the problem.

Knowledge changing. The opportunity that the new concept mapping instruction provides for a manipulation of nodes in the maps can change dominant thinking patterns and create new ones. The new method proposes some easy to apply techniques that stimulate creating of original and unconventional ideas. The new concept mapping instruction challenges the assumption that it 
is not possible to modify old pattern in such extent that it can result in creating a perfectly new one (De Bono, 1990).

There are not sufficient data to claim that learning style is a strong predictor for a differential effect on mapping production. However, some of the figures in the analysis of the mapping production suggest that learning style preferences should not be ignored. The analysis did not confirm the hypothesis predicting an interaction effect between the type of instruction and learning style. There might be two possible explanations for not confirming this hypothesis. The first one reflected the fact that the experiment modeled a situation, which was dealing primarily with problem-solving and in a less extent with learning. The second reason was the selection of a right measuring instrument. Although the Learning Style Questionnaire (Honey \& Mumford, 1992) solved some of the reliability problems of Learning Style Inventory (Kolb, 1998), it still returned inconsistent data due to measuring three different independent constructs: style, level and process (see for more details De Ciantis \& Kirton, 1996).

\section{Conclusions}

The instruction on concept mapping that includes problem-solving heuristics proved a better approach in ill-structured problem situations than the classical concept mapping instruction. The new instruction on concept mapping creates conditions for effective knowledge elicitation, knowledge representation, knowledge reflection and knowledge changing. However, the experimental results should be carefully generalized as more research is needed not only related to concept mapping instruction, but also to the role of instruction on other problem-solving tools.

We reported data related to the role of concept mapping instruction only in the analysis of problem situation and the idea generation phases. The problem-solving process includes 
additionally at least the phases of idea selection and solution implementation. We have some data about the role of problem-solving instruction in these problem-solving phases. However, the graphical techniques used in the idea selection and the solution implementation were not properly concept maps. Matrix for example seemed more appropriate graphical technique for idea selection. A sort of PERT diagram was used for the solution implementation phase. It would be useful to study the effectiveness of different graphical techniques, including concept mapping, for selecting ideas and implementing of the solutions. Individual differences can be tested also as a predictor for the preferences of learners to particular graphical technique. Further research on concept mapping instruction should optimize some of the experimental conditions developed for the purposes of the current study. The coding of the types of nodes needs an improvement. The indicators for knowledge reflection should be explicitly included in the map production scoring schema. Having clusters and different versions of maps' structures could be indicators for knowledge reflection.

We gave students in this study a domain independent problem with an idea to include experimental subjects from other faculties and universities. Follow up research should challenge students with a domain specific problem. For our reference situation such a problem could be designing a web site for educational or training purpose.

The experiment for determining the role of instruction for solving ill-structured problems reflected primarily problem-solving as learning being a secondary concern. Further research should better model the situation of learning to solve ill-structured problems. The individual differences should be better represented through a selection of an appropriate instrument. Most of the mapping approaches are supported by software (Inspiration ${ }^{\circledR}, 2004$, Mind Manager $^{\circledR}, 2004$, Decision Explorer ${ }^{\circledR}, 2004$, STELLA, 2000, and Idons-for-Thinking, 1999), 
which makes easier and more efficient the construction of a map and the manipulation of nodes and links. Testing the effectiveness of the instruction embedded in different mapping software applications could be the next research challenge.

Further research can include on a conceptual level the assumption of a possible interaction between the indicators of mapping production. The statistical test should check the sums-ofsquares and cross-products matrices (SSCP) for determining the effect of type of instruction on the means of various groupings of a joint distribution of these indicators.

\section{References}

Alpert, Sh. (2004). Flexibility of expressiveness: state of the practice. Conceptual representation for in-depth learning. In P. Kommers (Ed), Cognitive support for learning (pp.253 268). Amsterdam: IOS Press.

Buzan, T., \& Buzan, B. (1996). The Mind map. Book. New York: Plume.

Constantinou, C. (2004). Concept mapping for performance assessment in physics. In P.

Kommers (Ed), Cognitive support for learning (pp. 155 - 165). Amsterdam: IOS Press.

De Bono, E. (1990). Lateral thinking for management. London: Penguin Books.

De Cinatis, S. \& Kirton, M. (1996). A psychometric reexamination of Kolb's experiental learning cycle construct: a separation of level, style, and process. Educational and Psychological Measurement, 56 (5), 809-820.

Decision Explorer ${ }^{\circledR}$ [Computer software]. (2003). Banxia ${ }^{\circledR}$ Software: Kendal, Cumbria, UK.. Duncker, (1945). On problem solving. Psychological Monographs, 58 (Whole No. 270) 
Eden, C., \& Ackerman, F. (2002). Making strategy. The journey of strategic management. London: SAGE Publication.

Eysenk, M., \& Keane, M. (2000). Cognitive Psychology. London: LEA.

Fernández, H., Kommers, P., \& Asensio, M. (2004). Conceptual representation for in-depth learning. In P. Kommers (Ed), Cognitive support for learning (pp.229 - 240). Amsterdam: IOS Press.

Ge, X., \& Land, S. (2004). A Conceptual framework for scaffolding ill-structured problemsolving process using question prompts and peer interaction. Educational Technology Research and Development, 52 (2), 5-22.

Gordon, W. (1961). Synectics. New York: Harper \& Row.

Guilford, J.P. (1967). The nature of human Intelligence. N.Y: McGraw-Hill.

Gulmans, J. (2004). Mapping for the constructivistic acquisition of concepts? In P. Kommers (Ed), Cognitive support for learning (pp. 31-45). Amsterdam: IOS Press.

Heeren, E., \& Kommers, P. (1992). Flexibility of expressiveness: Critical factor in the design of concept. Mapping tools for learning. In P. Kommers, et al. (Eds), Cognitive tools for learning (pp. 86- 101). Berlin: Springer-Verlag.

Hodgson, A. (1999). Hexagons for systems thinking. Retrieved March 16, 1999 from WWW: http://www.orglearn.nl/Archives/Hexagons/hex1.rtft.html

Honey, P., \&. Mumford, A. (1992) The Manual of learning styles. Maidenhead, Berkshire: Published and Distributed by Peter Honey.

Huai, H. (2000). Cognitive styles: its relations to memory capacity and concept mapping. 
(Doctoral Dissertation, University of Twente, The Netherlands). Enschede: Febodruck.

Huai, H. , \& Kommers, P. (2004). Cognitive styles and concept mapping. In P. Kommers (Ed), Cognitive support for learning (pp. 209 - 228). Amsterdam: IOS Press.

Idons-For-Thinking 2.0 [Computer software, demo version]. (1999). Idon Software. Downloaded March, 16, 1999 from WWW: http://www.idonresources.com/demo.html

Inspiration ${ }^{\circledR}$ [Computer software]. (2003). Inspiration Software, Inc: Beaverton Hillsdale, Portland

Jonassen, D., Beissner. K., \& Yacci, M. (1993). Structural knowledge. New Jersey: LEA.

Jonassen, D., Reeves, T., Hong, H., Harvey, D., \& Peters, K. (1998). Concept mapping as cognitive learning and assessment tools. Journal of Interactive Learning Research, 8 (3/4) 289-308.

Jonassen, D. H. (2004). Learning to solve problems. An Instructional design guide. San Francisco, CA: Pffeifer.

Kaufmann, G. (2001). Problem-solving and creativity. In J. Henry (Ed.), Creative management (pp. 47-78). London: Sage.

Kennedy, D., \& McNaught (1998). Use of concept mapping in the design of learning tools for interactive multimedia. Journal of Interactive Learning Research, 8 (3/4) 389-406.

Kepner, Ch., \& Tregoe, B. (1981). The new rational manager. London: John Martin Publishing. King (1991). Effect if training in strategic questioning on children's' problem-solving performance. Journal of Educational Psychology, 83 (3), 307-317) 
Kolb, D. (1998). Experiential Learning. Englewood Cliffs, New York: Prentice-Hall.

Kommers, P., \& Lanzing, J. (1998). Students' concept mapping for hypermedia design:

Navigation through world wide web (www) space and self-assessment. Journal of Interactive Learning Research, 8 (3/4) 421-456.

Laffey, J., \& Singer, J. (1998). Using mapping for cognitive assessment in project-based science. Journal of Interactive Learning Research, 8 (3/4), 363- 388.

Lane, D. (1997). Modelling as learning: A consultancy methodology. In J. Morecroft \& J. Sterman (Eds.), Modeling for learning organizations (pp. 93 - 120). Portland, Oregon: System Dynamics Series, Productivity Press.

Lumer, J., \& Hesse, M. (2004). Concept mapping in the teaching of biology. In P. Kommers (Ed), Cognitive support for learning (pp. 81- 89). Amsterdam: IOS Press.

Lumer, J. \& Ohly, K.-P. (2004). In P. Kommers (Ed), Cognitive support for learning (pp. 8189). Amsterdam: IOS Press.

Luchins, A., \& Luchins, E. (1991). Task complexity and order effects in computer presentation of water jar problems. Journal of General Psychology, 118, 45-72.

Miles, M. B., \& Huberman, A. M. (1994). Qualitative data analysis. (Sec. Ed.). Thousand Oaks: Sage Publication.

Mind Manager ${ }^{\circledR}$ [Computer software]. (2002). Mindjet ${ }^{\mathrm{TM}}$ : Larkspur, CA.

Mintzberg, H. (1992). The Manger's job: Folklore and fact. In: H. Mintzberg, \& J. B. Quin. The strategy process concepts and contexts (pp.21-31). Englewood Cliffs, New Jersey: Prentice Hall. 
Newell, A., \& Simon, H. (1972). Human problem-solving. Englewood Cliffs, New York: Prentice Hall.

Novak, J., \& Gowin, D. (1984). Learning how to learn. Cambridge: Cambridge University Press.

Novak, J. (1998). Learning, creating and using knowledge. Concept maps . as facilitative tools in schools and corporation. Mahwah, New Jersey: LEA.

Oughton, J. M., \& Reed, W. M. (2000). The effect of hypermedia knowledge and learning styles on student-centered concept maps about hypermedia. Journal of research on computing in education, 32 (3), $366-383$.

Reimann, P. (1999). The role of external representations in distributed problem-solving. Learning

and Instruction, 9, 411-418.

Schön, D. (1996). The reflective practitioner. How professionals think in action. London: Arena.

Sherry, L., \& Trigg, M. (1996). Epistemic forms and epistemic games. Educational Technology, $36(3), 38-44$.

Spiro, R., \& Jehng, J.-C. (1990). Cognitive flexibility and hypertext: theory and technology for the nonlinear and multidimensional traversal of complex subject matter. In D. Nix \& R. Spiro (Eds.), Cognition, education and multimedia. Exploring ideas in high technology (pp. 163-205). Hillsdale, New Jersey: LEA.

STELLA 7.0 [Computer software, demo version]. (2000). High Performance System, Inc. The System Thinking Company. Downloaded November 19, 2000 from WWW: http://www.hps-inc.com/ 
Stoyanov, S. (2001). Mapping in the educational and training design. Doctoral dissertation, University of Twente, the Netherlands. Enschede: Print Partners Ipskamp.

Sweller, J., van Merrienboer, J., \& Paas, F. (1998). Cognitive architecture and instructional design. Educational Psychology Review, 10, 251-296.

Van Gundy, A. (1997). Techniques of structured problem-solving. New York: Van Nostrand.

Vennix, J. (1997). Group model building. Facilitating team learning using system dynamics. Chichester: John Wiley \& Sons.

Vygotsky, L. (1978). Mind and society. Cambrigde, MA: Harvard University Press.

Wagner, R. (1992). Managerial problems solving, In: R. Sternberg, \& P. Frensch (Eds.), Complex

problem-solving (159-184). Hillsdale, New Jersey: LEA

Wandersee, J. (1990). Concept mapping and the cartography of cognition. Journal of Research in Science Teaching, 27 (10), 923-936.

Weber, S. (2004). Evaluating structural knowledge with concept mapping. In P. Kommers (Ed), Cognitive support for learning (pp. 123 - 136). Amsterdam: IOS Press.

Wertheimer, M. (1987). Productive thinking. New York: Harper \& Brothers Publishers. (Original work published 1943)

Willerman, M., \& Harg, R. A. (1991) The concept map as an advance organizer. Journal of Research in Science Teaching, 28, (8), 705-711.

Wodtke, M. von (1993). Mind over media. New York: McGraw-Hill. 
